\title{
Two-stage corrective surgery for severe rigid cervical kyphotic deformity with unilateral vertebral artery occlusion after old blunt trauma: a case report
}

\author{
Tsunehiko Konomi $^{1,2} \cdot$ Kota Suda $^{1} \cdot$ Satoko Matsumoto ${ }^{1} \cdot$ Miki Komatsu $^{1} \cdot$ Masahiko Takahata $^{3} \cdot$ Norimasa Iwasaki $^{3}$. \\ Akio Minami ${ }^{1}$
}

Received: 9 January 2018 / Revised: 2 February 2018 / Accepted: 4 February 2018

(c) International Spinal Cord Society 2018

\begin{abstract}
Introduction There are considerable risks for vertebral artery (VA) injury in case of corrective surgery for a severe and rigid cervical kyphotic deformity. This case report describes a rare case of surgical management for pre-existing traumatic rigid cervical kyphosis associated with unilateral VA occlusion.

Case presentation A 73-year-old male fell down and injured his neck. He was referred to our hospital 10 months after injury because his degree of head drop progressed gradually to a chin-on-chest position such that he could not look straight forward. On plain X-ray, the C2-7 angles in the neutral, flexion, and extension positions were $61^{\circ}, 71^{\circ}$, and $50^{\circ}$, respectively. CT revealed a collapse of the C5 vertebral body and bone fusion between $\mathrm{C} 4$ and $\mathrm{C} 5$ in the anterior vertebrae, and unilateral VA occlusion was confirmed by angiography. Two-stage surgery was planned to correct the kyphosis. In the first stage, anterior release of the $\mathrm{C} 4 / 5$ bone-spur fusion and dissection of the intervertebral disk were performed. After release, angiography confirmed neither occlusion nor rupture of the VA. In the second stage, anterior and posterior fixation was performed at correcting position while maintaining slight kyphosis in order to avoid excessive distortion of the VA. The postoperative C2-7 kyphosis angle improved to $16^{\circ}$ without any VA injury, and the patient could look forward easily. Discussion The degree of correction as well as risk management of VAs should be considered carefully during corrective surgery for severe and rigid cervical kyphosis, especially with unilateral VA occlusion.
\end{abstract}

\section{Introduction}

There are considerable risks for vertebral artery (VA) injury in corrective surgery of a cervical deformity; therefore, adequate risk management is necessary to avoid VA injury. Here, we describe a rare case of surgical management for pre-existing traumatic rigid cervical kyphosis associated

Tsunehiko Konomi

konomitsunehiko@gmail.com

1 Department of Orthopedic Surgery, Hokkaido Spinal Cord Injury Center, 3-1 Higashi-4 Minami-1, Bibai, Hokkaido 072-0015, Japan

2 Department of Orthopedic Surgery, Murayama Medical Center, National Hospital Organization, 2-37-1 Gakuen, Musashimurayama, Tokyo 208-0011, Japan

3 Department of Orthopedic Surgery, Graduate School of Medicine, Hokkaido University, Kita 8, Nishi 5, Kita-ku, Sapporo, Hokkaido 060-0808, Japan with unilateral VA occlusion. We highlight the importance of evaluating VAs and the appropriate degree of correction for cervical kyphosis.

\section{Case presentation}

The patient was a 73-year-old male with mental retardation who was living at a special care facility. He could perform the activities of daily living independently and had neither a specific motor disability nor appreciable disease. He fell down and injured his neck 1 year earlier, but the underlying mechanism of the injury was unclear. He had been treated conservatively at an orthopedic clinic, and no neurological deficit was seen. However, he was referred to our hospital at 10 months after injury because his degree of head drop progressed gradually to the extent that he could not look straight forward. He could not walk safely because his visual field was lower.

At the initial examination, his head had dropped to a chin-on-chest position. Moreover, his neck was so rigid that 

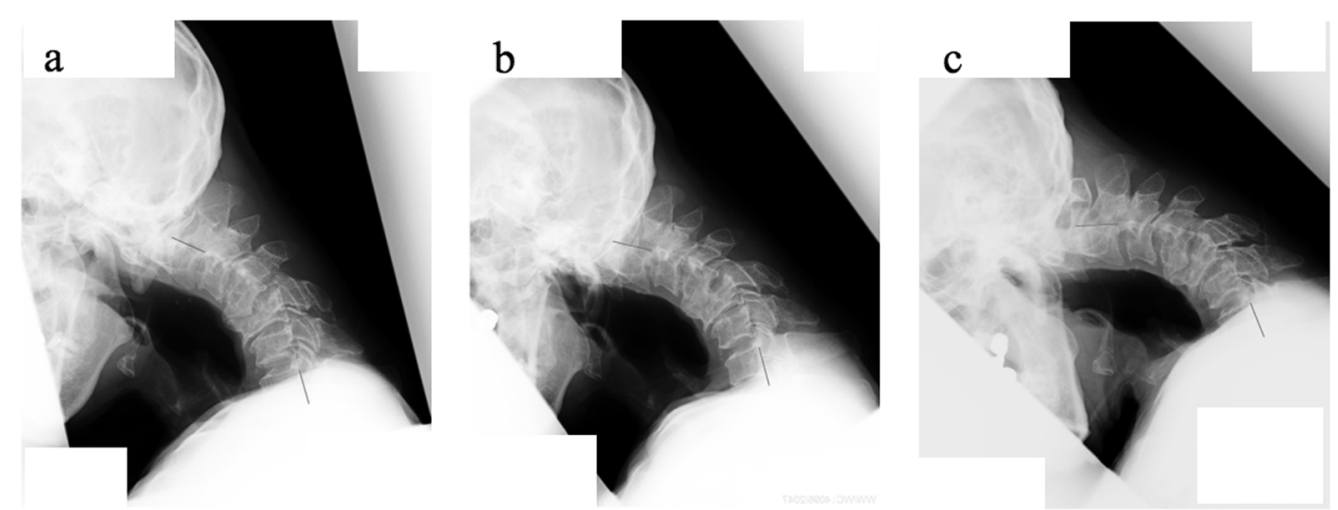

Fig. 1 Cervical kyphotic deformity was observed on plain X-ray (lateral view), and C2-7 kyphotic angles in extension (a), neutral (b), and flexion (c) positions were $50^{\circ}, 61^{\circ}$, and $71^{\circ}$, respectively

Fig. 2 Preoperative sagittal view of CT (a) and T2-weighted MRI (b) revealed collapse of the $\mathrm{C} 5$ vertebral body, bone spur fusion in the anterior vertebrae, and disassociation of the interspinous process interval between $\mathrm{C} 4$ and $\mathrm{C} 5$. On MRI, no obvious cord compression was observed
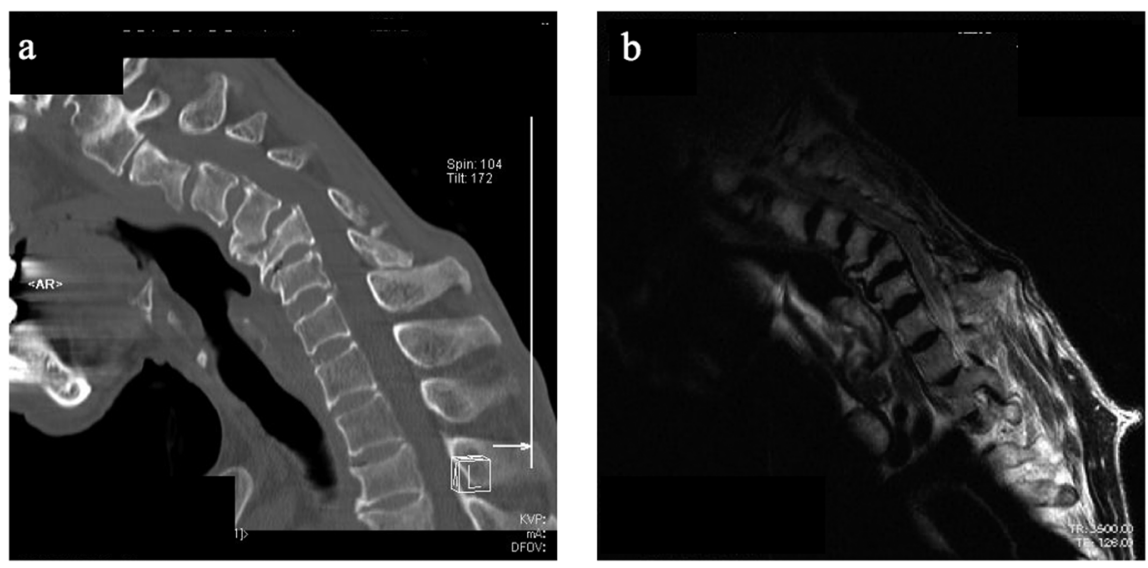

it could not be extended passively. There was no observable neurological deficit. On plain X-ray, a kyphotic deformity was seen by functional imaging of the cervical spine; $\mathrm{C} 2-7$ angles in the extension (a), neutral (b), and flexion (c) positions were $50^{\circ}, 61^{\circ}$, and $71^{\circ}$, respectively (Fig. 1). Computed tomography (CT) revealed a collapse of the C5 vertebral body, bone spur fusion in the anterior vertebrae, and disassociation of the interspinous process interval between $\mathrm{C} 4$ and $\mathrm{C} 5$. On T2-weighted sagittal images from magnetic resonance imaging (MRI), no obvious cord compression was observed (Fig. 2). An occlusion of the right VA was confirmed in CT and MR angiography (Fig. 3). Taken together, the patient was diagnosed as delayed kyphotic deformity associated with VA occlusion following cervical spine trauma. With an aim to improve his frontal gaze disturbance and kyphotic deformity, surgical correction and fixation of the cervical spine was performed.

Two-stage surgery was planned. In the first stage, anterior release of the C4-5 bone-spur fusion and dissection of the intervertebral disk were performed (surgery time: $200 \mathrm{~min}$; estimated blood loss: $15 \mathrm{~mL}$ ). After release, the cervical spine was distracted and extended gradually as much as possible and a hard collar was applied for external fixation. Then, the VA was evaluated by CT angiography. At this time, C2-7 kyphosis angle was $35^{\circ}$ without any progression of VA occlusion associated with cervical spine extension.

In the second stage, at 2 days after the initial surgery, posterior release and instrumental fixation with pars and pedicle screws on C2-7 and anterior corpectomy of the C5 vertebral body with implantation of an autologous ilium bone were performed (surgery time: $360 \mathrm{~min}$; estimated blood loss: $339 \mathrm{~mL}$ ). After surgery, C2-7 kyphosis angle improved to $16^{\circ}$ (Fig. 4). On postoperative CT and MR angiography, no progression of VA occlusion was confirmed (Fig. 5). The patient's visual field became upper and wider and he could look forward easily. He was discharged and neurological impairment has not been observed consistently until 12 months post surgery.

\section{Discussion}

Cervical malalignment contributes to the pathogenesis of cervical myelopathy. It has been shown, in cadaver and 
Fig. 3 Right VA occlusion was confirmed on CT (a sagittal view of the right VA; $\mathbf{b}$ axial view; $\mathbf{c}$ sagittal view of the left VA) and MR angiography (d)
Fig. 4 Postoperative $\mathrm{C} 2-7$ kyphotic angle improved to $16^{\circ}$ (a lateral view of X-ray; $\mathbf{b}$ sagittal view of $\mathrm{CT}$ )
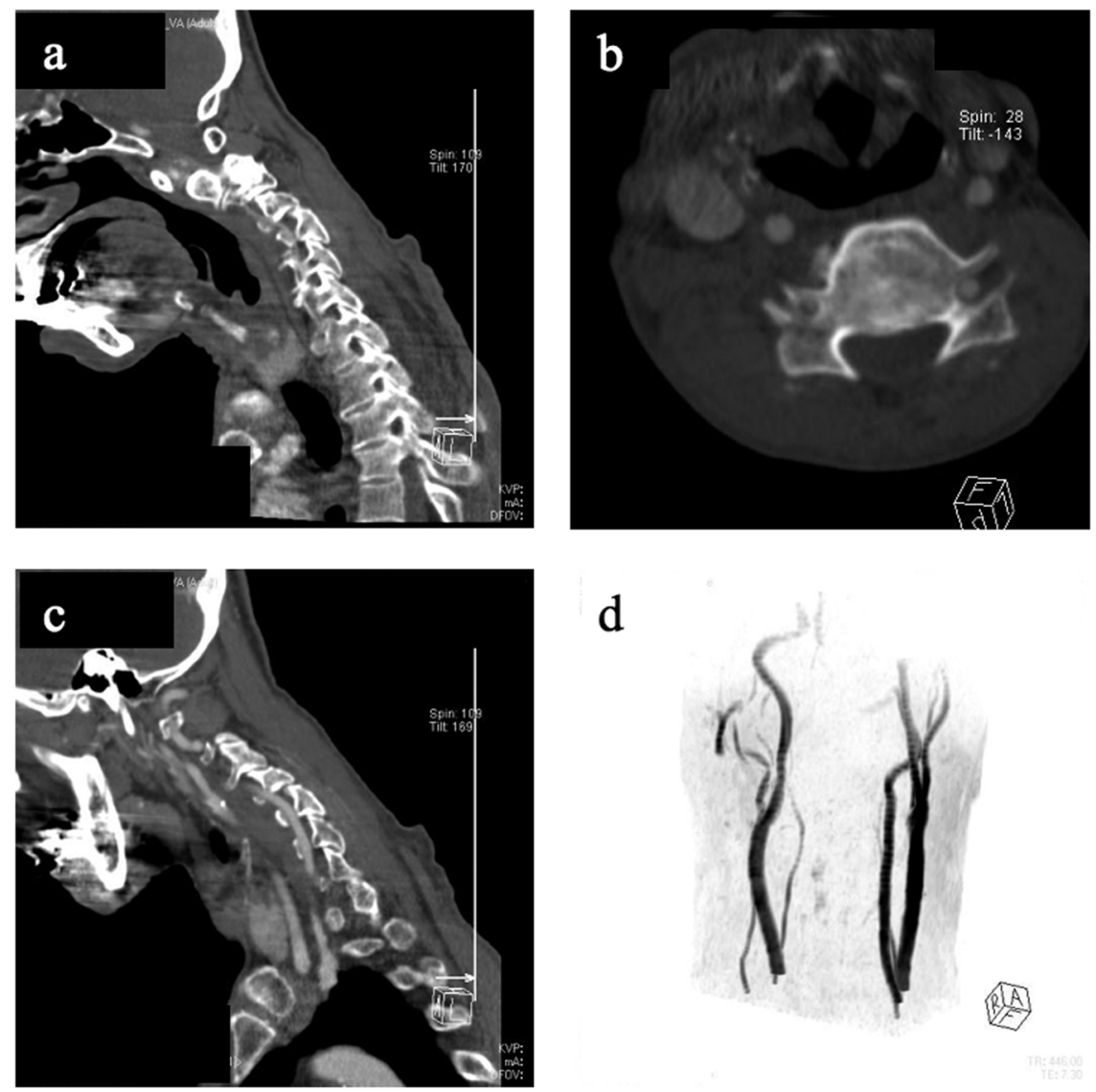

d
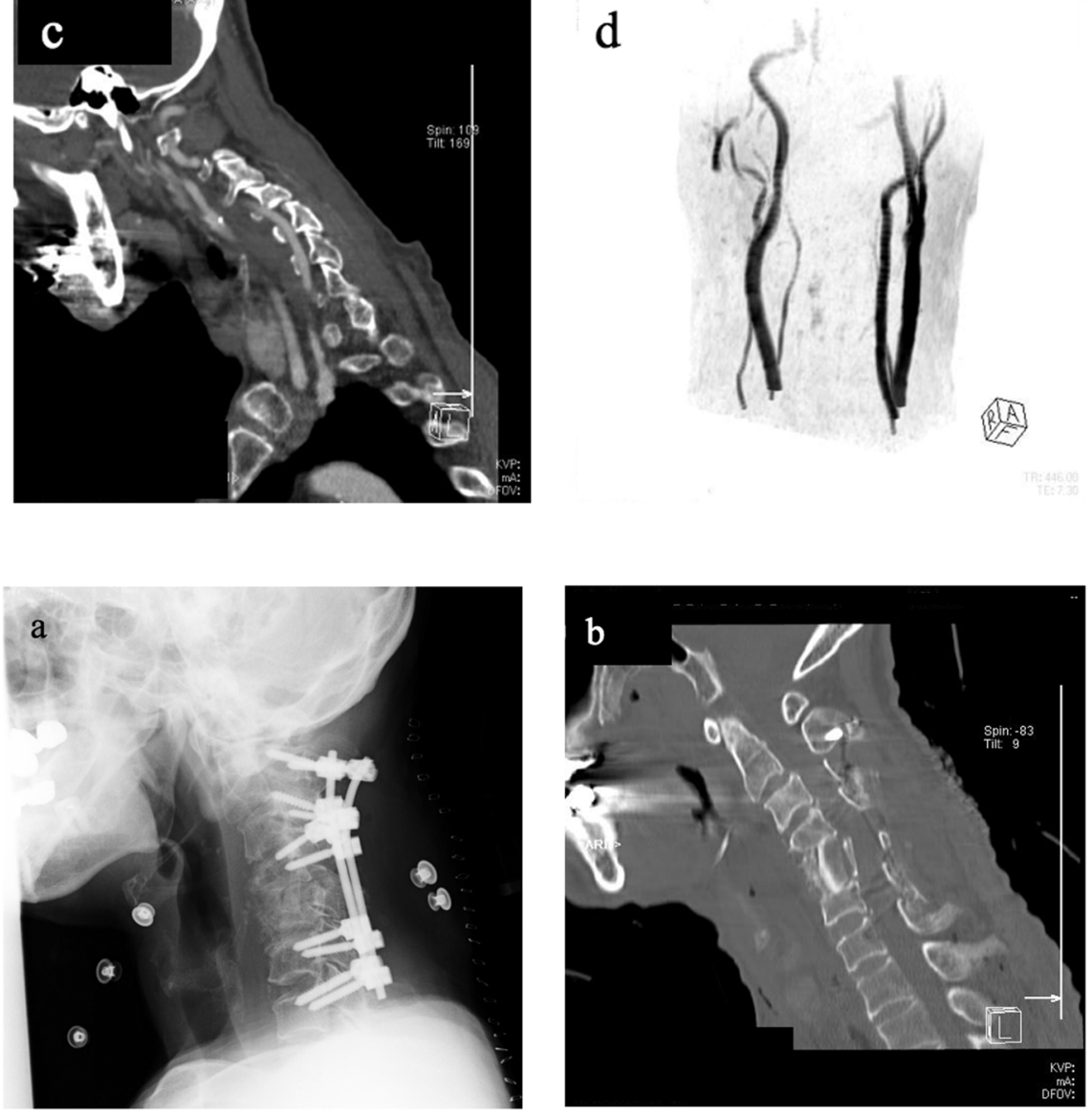

animal models, that an increase in sagittal kyphosis leads to greater cord tension, flattening, and an increase in intramedullary pressure, resulting in neurological compromise [1-6]. VA injury accounts for $17-46 \%$ of cervical spine traumas, of which $0-45 \%$ are symptomatic and $0-18 \%$ are considered life-threatening complications [7-14]. It is also reported that $50-70 \%$ of traumatic VA injury is accompanied with a cervical spine fracture and spinal cord injury [8]. When performing posterior cervical spinal instrumentation surgery, precise evaluation of VA and circle of
Willis is usually required to avoid VA injury and concurrent associated complications [15-17].

As far as we are aware, the incidence of VA injury during corrective surgery of the cervical spine is unclear. However, complications of related medical procedures for cervical kyphosis have been reported [17-22]. Horsley reported longitudinal traction-induced rupture of VA aneurysm in a case with neurofibromatosis type I and severe cervical kyphosis [23]. Willis reported that there are potential risks for embolus formation associated with 
Fig. 5 There was no progression of VA occlusion on postoperative CT (a sagittal view of the right VA; $\mathbf{b}$ axial view; c sagittal view of the left VA) and MR angiography (d)
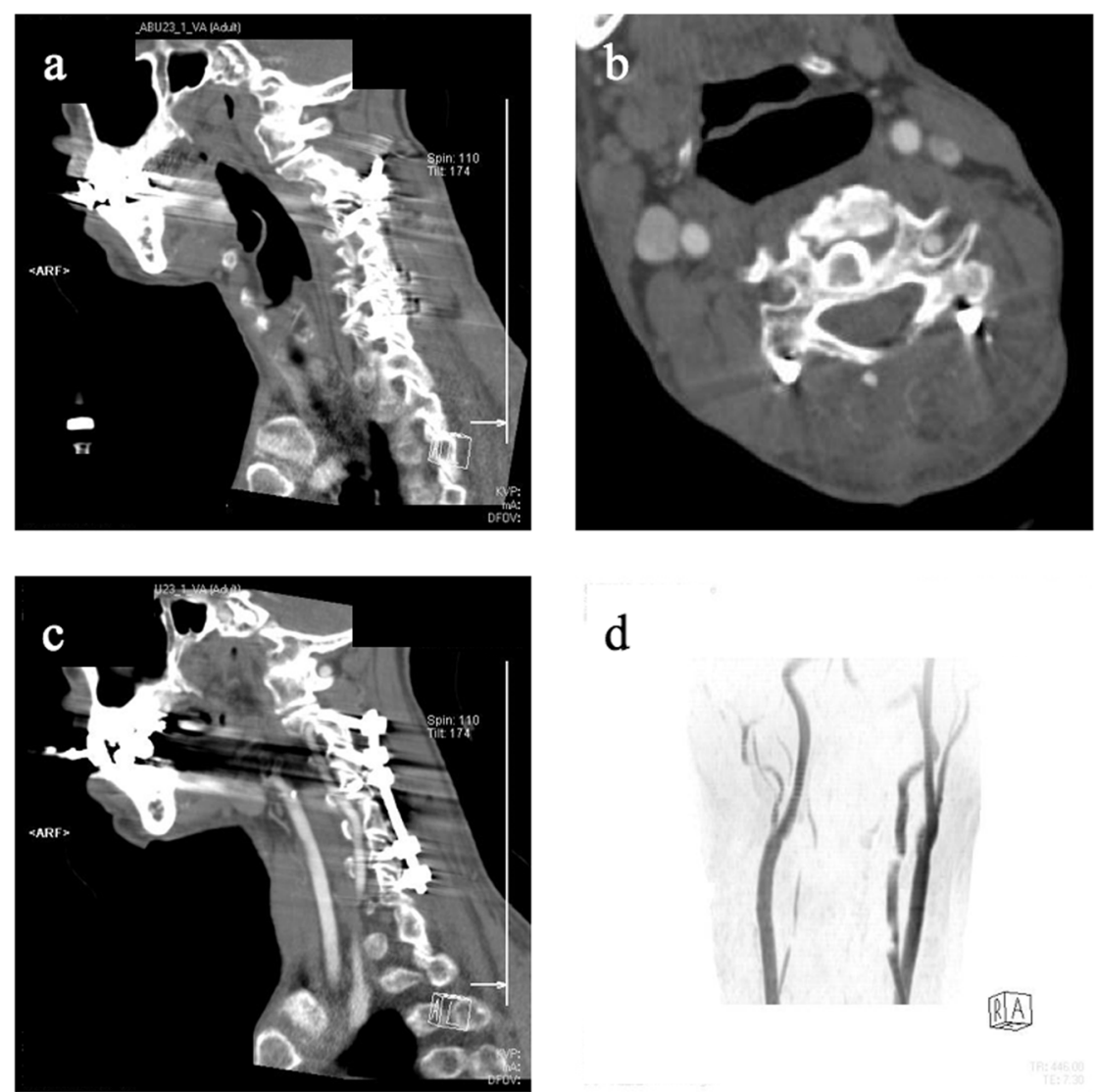

d

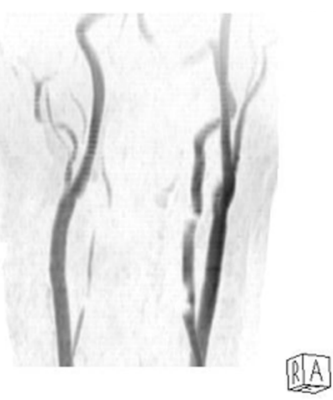

vasospasm or intimal injury when VA is distorted and/or stretched due to fracture dislocation [13]. Thus, before surgical reduction or/and correction, VAs should be evaluated by angiography to reduce the risk of VA injury [24].

In this case, we performed corrective fusion surgery for delayed rigid kyphotic deformity of the cervical spine associated with unilateral VA occlusion. To prevent damage to the existing dominant VA, we evaluated the VAs in neckextended position by angiography, when cervical spine mobility was obtained by anterior release. After confirming the safety of the dominant VA, we then performed anterior and posterior fixation at the correcting position. Excessive correction might lead to vasospasm, rupture, or occlusion of the dominant VA, which could result in brain stem damage that might be fatal. Therefore, we were prepared to discontinue the correction if any sign of VA injury was observed. Fortunately, no sign of progression was confirmed during the first stage of surgery, and we proceeded to the second stage of surgery 2 days later. Although we avoided excessive correction and left some kyphosis (postoperative C2-7 kyphotic angle improved to $16^{\circ}$ ), frontal gaze disturbance was resolved and the patient has been able to lead a normal daily life.

In conclusion, it is important that not only adequate risk management for VAs but also appropriate correction should be considered carefully for corrective surgery of cervical kyphosis, especially in patients with unilateral VA occlusion.

\section{Compliance with ethical standards}

Conflict of interest The authors declare that they have no conflict of interest.

\section{References}

1. Jarzem PF, Quance DR, Doyle DJ, Begin LR, Kostuik JP. Spinal cord tissue pressure during spinal cord distraction in dogs. Spine. 1992;17(8 Suppl):S227-34.

2. Iida $\mathrm{H}$, Tachibana $\mathrm{S}$. Spinal cord intramedullary pressure: direct cord traction test. Neurol Med Chir. 1995;35:75-7.

3. Kitahara Y, Iida H, Tachibana S. Effect of spinal cord stretching due to head flexion on intramedullary pressure. Neurol Med Chir. 1995;35:285-8.

4. Tachibana S, Kitahara Y, Iida H, Yada K. Spinal cord intramedullary pressure. A possible factor in syrinx growth. Spine. 1994;19:2174-8. discussion 2178-9.

5. Shimizu K, Nakamura M, Nishikawa Y, Hijikata S, Chiba K, Toyama Y. Spinal kyphosis causes demyelination and neuronal loss in the spinal cord: a new model of kyphotic deformity using juvenile Japanese small game fowls. Spine. 2005;30:2388-92.

6. Chavanne A, Pettigrew DB, Holtz JR, Dollin N, Kuntz Ct. Spinal cord intramedullary pressure in cervical kyphotic deformity: a cadaveric study. Spine. 2011;36:1619-26. 
7. Desouza RM, Crocker MJ, Haliasos N, Rennie A, Saxena A. Blunt traumatic vertebral artery injury: a clinical review. Eur Spine J. 2011;20:1405-16.

8. Fassett DR, Dailey AT, Vaccaro AR. Vertebral artery injuries associated with cervical spine injuries: a review of the literature. $\mathbf{J}$ Spinal Disord Tech. 2008;21:252-8.

9. Friedman D, Flanders A, Thomas C, Millar W. Vertebral artery injury after acute cervical spine trauma: rate of occurrence as detected by MR angiography and assessment of clinical consequences. AJR Am J Roentgenol. 1995;164:443-7. discussion $448-9$

10. Giacobetti FB, Vaccaro AR, Bos-Giacobetti MA, Deeley DM, Albert TJ, Farmer JC, et al. Vertebral artery occlusion associated with cervical spine trauma. A prospective analysis. Spine. 1997;22:188-92.

11. Louw JA, Mafoyane NA, Small B, Neser CP. Occlusion of the vertebral artery in cervical spine dislocations. J Bone Jt Surg Br. 1990;72:679-81.

12. Taneichi H, Suda K, Kajino T, Kaneda K. Traumatically induced vertebral artery occlusion associated with cervical spine injuries: prospective study using magnetic resonance angiography. Spine. 2005;30:1955-62.

13. Willis BK, Greiner F, Orrison WW, Benzel EC. The incidence of vertebral artery injury after midcervical spine fracture or subluxation. Neurosurgery. 1994;34:435-41. discussion 441-2

14. Woodring JH, Lee C, Duncan V. Transverse process fractures of the cervical vertebrae: are they insignificant? J Trauma. 1993;34:797-802.

15. Harrigan MR, Hadley MN, Dhall SS, Walters BC, Aarabi B, Gelb DE. et al. Management of vertebral artery injuries following nonpenetrating cervical trauma. Neurosurgery. 2013;72(Suppl 2):234-43.
16. Biffl WL, Ray CE Jr, Moore EE, Franciose RJ, Aly S, Heyrosa MG, et al. Treatment-related outcomes from blunt cerebrovascular injuries: importance of routine follow-up arteriography. Ann Surg. 2002;235:699-706. discussion 706-7

17. Abumi K, Shono Y, Ito M, Taneichi H, Kotani Y, Kaneda K. Complications of pedicle screw fixation in reconstructive surgery of the cervical spine. Spine. 2000;25:962-9.

18. Wang JC, Buser Z, Fish DE, Lord EL, Roe AK, Chatterjee D. et al. Intraoperative death during cervical spinal surgery: a retrospective multicenter study. Glob Spine J. 2017;7(1 Suppl):127S-31S.

19. Petheram TG, Hourigan PG, Emran IM, Weatherley CR. Dropped head syndrome: a case series and literature review. Spine. 2008;33:47-51.

20. Hsu WK, Kannan A, Mai HT, Fehlings MG, Smith ZA, Traynelis VC. et al. Epidemiology and outcomes of vertebral artery injury in 16582 cervical spine surgery patients: an AOSpine North America multicenter study. Glob Spine J. 2017;7(1 Suppl):21S-7S.

21. Grosso MJ, Hwang R, Krishnaney AA, Mroz TE, Benzel EC, Steinmetz MP. Complications and outcomes for surgical approaches to cervical kyphosis. J Spinal Disord Tech. 2015;28:E385-93.

22. Gerling MC, Bohlman HH. Dropped head deformity due to cervical myopathy: surgical treatment outcomes and complications spanning twenty years. Spine. 2008;33:E739-45.

23. Horsley M, Taylor TK, Sorby WA. Traction-induced rupture of an extracranial vertebral artery aneurysm associated with neurofibromatosis. A case report. Spine. 1997;22:225-7.

24. Komatsu M, Suda K, Takahata M, Matsumoto S, Ushiku C, Yamada K, et al. Delayed bilateral vertebral artery occlusion after cervical spine injury: a case report. Spinal Cord Ser Cases. 2016;2:16031. 